\title{
Phosphoric Acid-Mediated Depolymerization and Decrystallization of $\alpha$-Cellulose Obtained from Corn Cob: Preparation of Low Crystallinity Cellulose and Some Physicochemical Properties
}

\section{F.O. Ohwoavworhua* and T.A. Adelakun}

Department of Pharmaceutical Technology and Raw Materials Development (PT\&RMD), National Institute for Pharmaceutical Research and Development,

(NIPRD), P.M.B. 21, Abuja, Nigeria

\begin{abstract}
Purpose: Low crystallinity celluloses (LCC) are materials that have a substantially reduced degree of crystallinity, typically ranging between 15 and $45 \%$. It is useful as an excipient in preparation of tablets and confectionery products. The aim of this work was to obtain from $\alpha$ cellulose content of corn cob, a low crystallinity cellulose (LCC-CC), and study its physical properties as well as evaluation of its potential as tablet excipient.

Methods: $\alpha$ - cellulose (AC-CC) obtained from corn cob by a delignification process, was depolymerized with $85 \%$ phosphoric acid to yield LCC-CC product, whose physical properties were compared with those of AC-CC.

Results: The yield of AC-CC and LCC-CC were 14 and $11 \%$, respectively. The physical properties indicated a good level of purity of the cellulose materials as they conform to British Pharmacopoeia specifications. The flow indices, however, showed that these materials flowed poorly.

Conclusion: It was concluded that LCC-CC is a potential disintegrant and filler-diluent, in pharmaceutical tableting.
\end{abstract}

Keywords: Low crystallinity cellulose, a-cellulose, physical properties, corn cob.

*Corresponding Author: E-mail: frankohwo@yahoo.com 


\section{Ohwoavworhua et al}

\section{INTRODUCTION}

The hydrolysis of cellulose by mineral acids has been extensively investigated for preparation of microcrystalline cellulose (MCC) the most commonly and widely used direct compression excipient in tableting ${ }^{1,2}$. MCC is currently marketed world-wide under various trade names and is characterized by a high degree of crystallinity. The crystallinity index typically ranges between $55 \%$ and $80 \%$ (as determined by the powder X-ray diffraction method), depending on the origin of the source, processing variables, such as reaction temperature and duration, mechanical agitation of the slurry, and drying conditions $s^{3,4}$.

Low crystallinity celluloses (LCC) are materials that have a substantially reduced degree of crystallinity, typically ranging between 15 and $45 \%$. LCC can be prepared either by mechanical disintegration of the cellulosic source (dry or wet milling) ${ }^{3,5,6}$ or from a chemical reaction between cellulose and concentrated mineral acids (e.g $37-42 \%$ concentrated hydrochloric acid at $30-$ $50^{\circ} \mathrm{C}, 65-75 \%$ sulfuric acid at $35-45^{\circ} \mathrm{C}$ for 10 min, and a mixture of hydrochloric and sulfuric acid or phosphoric acid at $\left.<50{ }^{\circ} \mathrm{C}\right)^{7,8}$. Compared to native and regenerated cellulose, low crystallinity cellulose shows improved dispersibility in water, increased compactibility with materials such as starches, proteins, and lipids, and is useful as an excipient in the preparation of tablets and confectionery products $^{9}$. As part of on-going efforts to develop local raw materials for the pharmaceutical industry, we have in the present work, obtained low crystallinity cellulose from the a-cellulose derived from corn cob. Corn cob waste has been identified in various studies as a potential source of cellulose ${ }^{10,11}$. The $\alpha$ - and low crystallinitycelluloses (coded AC-CC and LCC-CC, respectively) obtained were assessed for their physicochemical properties.

\section{MATERIALS AND METHODS Materials}

Nitric acid, sodium nitrite, sodium sulphite, sodium hydroxide (BDH, England), sodium hypochlorite (JIK, ${ }^{\circledR}$ Reckitt and Colman Ltd., Nigeria), phosphoric acid and xylene (Vicker
Laboratories Ltd., England) were used. All other chemicals used were of analytical reagent grade and water was double-distilled.

Corn cob was obtained from a local corn mill in Idu, Abuja, Nigeria

\section{Methods}

Extraction of a-cellulose (AC-CC)

The method of Okhamafe et al ${ }^{10}$, with slight modification, was used. The corn cob was washed and cut into smaller pieces using cutlass and dried at $60^{\circ} \mathrm{C}$ for $48 \mathrm{~h}$ in a hot air oven (Kotterman, Germany). These were then crushed using the Apex mill (model 160, Apex Construction Ltd, London) and the fraction of particles size under $1.00 \mathrm{~mm}$ was used for extraction. A $300 \mathrm{~g}$ quantity of the material was treated with $4 \mathrm{~L}$ of $3.5 \%$ nitric acid containing $40 \mathrm{mg}$ of sodium nitrite for $2 \mathrm{~h}$ in a stainless steel container immersed in a water bath (FGL 1083, Karl Kolb Scientific, West Germany) set at $90^{\circ} \mathrm{C}$ to remove lignin in the form of soluble nitrolignins. Following thorough washing and filtration, it was digested with a $3 \mathrm{~L}$ solution containing $2 \% \mathrm{w} / \mathrm{v}$ each of sodium hydroxide and sodium sulphite at a temperature of $50^{\circ} \mathrm{C}$ for 1h. Again, it was washed, filtered and bleached with a $2 \mathrm{~L} 1: 1$ aqueous dilution of $3.5 \% \mathrm{w} / \mathrm{v}$ sodium hypochlorite at boiling temperature for $0.5 \mathrm{~h}$. The washed and filtered material (i.e., holocellulose) was next treated with $2 \mathrm{~L}$ of $17.5 \%$ $\mathrm{w} / \mathrm{v}$ sodium hydroxide at $80^{\circ} \mathrm{C}$ for $0.5 \mathrm{~h}$. The resulting alpha cellulose was washed thoroughly with water. The extraction process was then completed by whitening with a 1:1 aqueous dilution of $3.5 \% \mathrm{w} / \mathrm{v}$ sodium hypochlorite for 5 min at $100^{\circ} \mathrm{C}$ and subsequent washing with water until filtrate was clear. The cellulose material was filtered, and the water manually squeezed out in a calico cloth to obtain small lumps, which were dried at $60^{\circ} \mathrm{C}$ in a fluidized bed dryer (model TG 1, Retsch $\mathrm{GmbH}$ \& Co., Germany ). Following further milling and sieving the fraction passing through $750 \mu \mathrm{m}$ sieve was obtained and used for further investigation. 


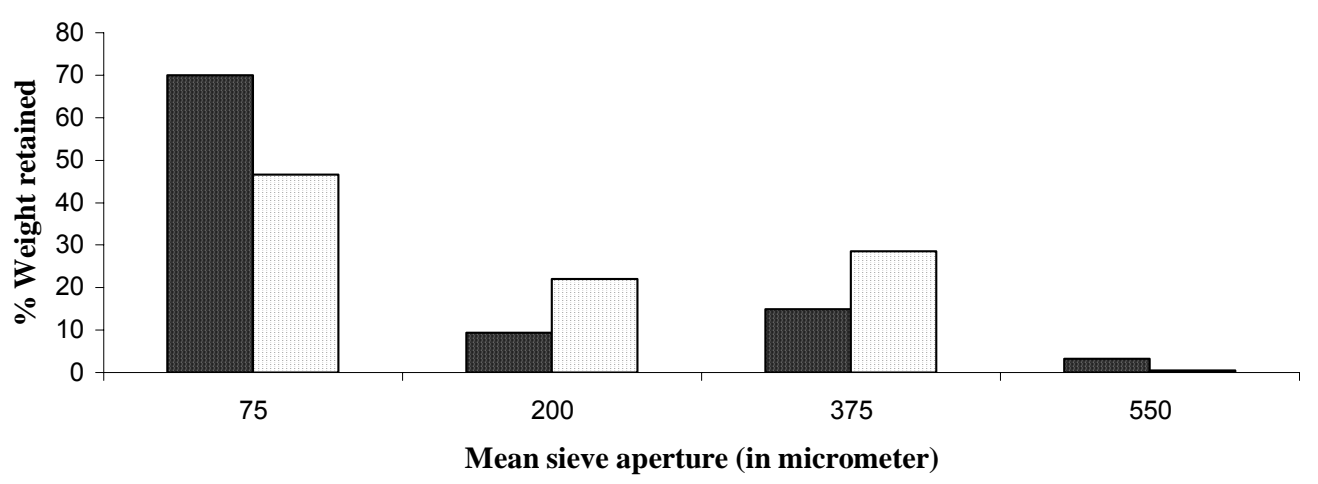

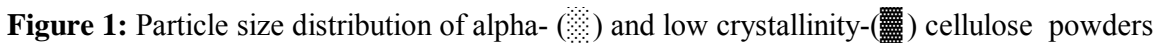
obtained from corn cobs

Preparation of low crystallinity cellulose (LCCCC)

LCC-CC was prepared according to the method of Wei et $\mathrm{al}^{12}$. Briefly, cellulose was reacted with $85 \%$ phosphoric acid, first at room temperature for $1 \mathrm{~h}$ and then at $50^{\circ} \mathrm{C}$ for $4 \mathrm{~h}$. The resulting translucent, viscous solution was cooled to room temperature and then added to five times the volume of water with constant agitation. The white solid precipitate was filtered and repeatedly washed with water until the $\mathrm{pH}$ of the filtrate was neutral. The wet cake was then suspended in acetone, and finally filtered. This process was repeated several times to ensure removal of water from the residue. The acetonewashed material was dried in air and sieved. The fraction of particle size $<650 \mu \mathrm{m}$ was collected and used in the study.

\section{Physicochemical properties of AC-CC and LCC-CC}

Determination of organoleptic characteristics, identification test, tests for presence of starch and dextrin, solubility and water-soluble substances of AC-CC and LCC-CC were carried out using the BP $2004^{13}$ methods. An optical microscope, Nikon Larphot 2 (Nikon Inc. Japan) was used for preliminary assessment of the nature of AC-CC and LCC-CC particles. The combination of low and high power objective lenses of $\times 100$ and $\times 400$ magnification were used.

$\mathrm{pH}$ determination: A $2 \mathrm{~g}$ quantity of the powder material was shaken with $100 \mathrm{ml}$ of distilled water for $5 \mathrm{~min}$ and the $\mathrm{pH}$ of the supernatant liquid determined using a $\mathrm{pH}$ meter (model 10, Corning, England).

\section{Powder Properties}

The particle size analysis, true density, flow properties, powder porosity, hydration capacity, swelling capacity, moisture sorption profile and loss on drying of the cellulose materials were determined.

Particle Size Analysis: The sieves of aperture size 150 to $850 \mu \mathrm{m}$ were arranged in descending order with a collector pan at the bottom and placed on a sieve shaker (, Endicott Ltd, UK). A $40 \mathrm{~g}$ quantity of cellulose powder was placed on the top sieve and shaken for 5 min. The weight of material retained on each sieve was then determined and the average diameter was calculated using the equation ${ }^{14}$ : 


\section{Ohwoavworhua et al}

Average diameter $=[\Sigma(\%$ retained $) \times($ mean aperture)]/100

end of the stem cut perpendicular to its axis of symmetry was secured with its tip $2 \mathrm{~cm}$ above a graph paper placed on a flat horizontal surface.

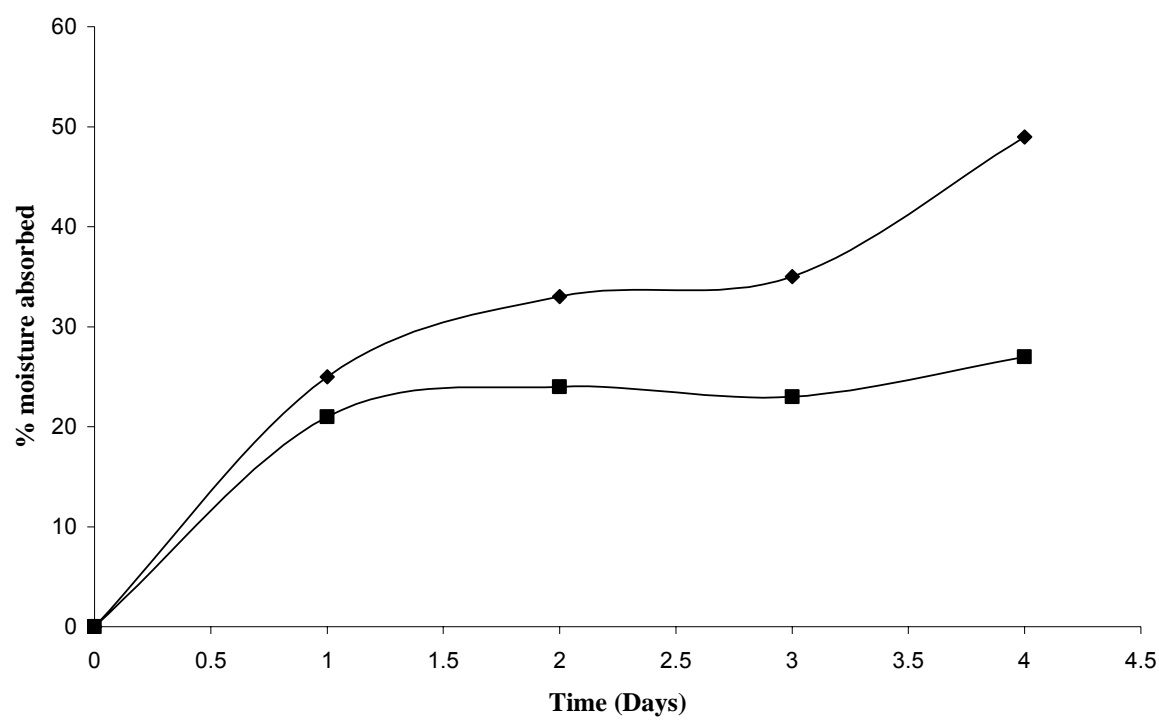

Figure 2: Percent moisture absorbed/Time (days). A moisture sorption profile of alpha- ( $\mathbf{\square})$ and low crystallinity- $(\bullet)$ cellulose powders obtained from corn cobs exposed to $100 \%$ relative humidity

True Density: This was determined by the specific gravity bottle method. A clean, dry $50 \mathrm{ml}$ specify gravity bottle was filled with xylene and its weight determined. Some of the xylene was poured out and $0.5 \mathrm{~g}$ of the cellulose material was placed inside. More xylene was added until the bottle was filled and was wiped dry of excess fluid. Its weight was again determined and the true density, $\left(D_{t}\right)$, calculated using equation (2). The determination was carried out in triplicate and the mean calculated.

$$
D_{t} \quad=\quad w /[(a+w)-b] \times S G
$$

Where $w$ is the weight of powder, SG is specific gravity of solvent, $a$ is weight of bottle + solvent and $b$ is weight of bottle + solvent + powder ${ }^{10}$, 11 .

\section{Flow properties}

Angle of Repose: The static angle of repose, $a$, was measured according to the fixed funnel and free standing cone method ${ }^{15}$. A funnel with the
Powder was carefully poured through the funnel until the apex of the cone thus formed just reached the tip of the funnel.

The mean diameter, (D), of the base of the powder cone was determined and the tangent of the angle of repose calculated using equation (3):

Tan $a=2 h / D$

Bulk and Tap Densities: A $10 \mathrm{~g}$ quantity of powder sample was placed in a $50 \mathrm{ml}$ clean, dry measuring cylinder and the volume, $\mathrm{V}_{\mathrm{o}}$, occupied without tapping was determined. After 500 taps using a Stampfvolumeter model STAV 2003 (JEF, Germany), the volume, $V_{500}$ was determined. The bulk, $\left(D_{b}\right)$, and tapped densities were calculated as the ratio of weight to volume $\left(\mathrm{V}_{0}\right.$ and $\mathrm{V}_{500}$, respectively) ${ }^{16}$.

Hausner Index: This was calculated using the bulk and tapped densities data obtained as above when fitted into equation (4) ${ }^{16}$. 


\section{Ohwoavworhua et al}

Hausner's ratio $=$ Tapped density/Bulk density (4)

Compressibility Index (C \%): This was also calculated using the bulk and tapped density data fitted into Eqn. (5) ${ }^{16}$.

Compressibility $=$ (tapped density - bulk density)/Tapped density $\times 100 \%$

Powder Porosity (e): This was derived from the values of true and bulk densities when fitted into the Eqn. (6): ${ }^{16}$

$e=1-D_{b} / D_{t} \times 100$

Hydration Capacity: The method of Kornblum and d Stoopak ${ }^{17}$ was used. A $1.0 \mathrm{~g}$ sample was placed in each of four $15 \mathrm{ml}$ plastic centrifuge tubes to which $10 \mathrm{ml}$ of distilled water was added and then stoppered. The contents were mixed on a vortex mixer (Vortex-Gennie Scientific Industry, USA) for 2 min. The mixture was allowed to stand for $10 \mathrm{~min}$ and then centrifuged at $1000 \mathrm{rpm}$ for $10 \mathrm{~min}$ on a bench centrifuge (Gallenkamp, England). The supernatant was carefully decanted, the stopper replaced and the sediment weighed. The hydration capacity $(\mathrm{Hc})$ was taken as the ratio of sediment weight to the dry sample weight.

Swelling Capacity: This was measured at the same time as the hydration capacity and calculated as follows:

$S=\left(V_{2}-V_{1}\right) / V_{1} \times 100$

Where $S$ is the \% swelling capacity, $V_{2}$ is the volume of the hydrated or swollen material and $V_{1}$ is the tapped volume of the material prior to hydration ${ }^{16}$.

Moisture Sorption Capacity: A 2 g quantity of the cellulose materials were accurately weighed and evenly distributed over the surface of a $70 \mathrm{~mm}$ tarred Petri dish. The sample was then placed in a desiccator containing distilled water $(\mathrm{RH}=$ $100 \%$ ) and stored at room temperature. At various time intervals, over a four-day period, the weight gained by the exposed sample was recorded and the amount of water sorbed was calculated from the weight difference ${ }^{16}$.

Loss on drying: $5 \mathrm{~g}$ powder samples were dried at $110^{\circ} \mathrm{C}$ to a constant weight. The $\%$ loss in weight was calculated as the moisture content 16

\section{RESULTS AND DISCUSSION}

The yield of $\alpha$-cellulose (AC-CC) was approx. $14 \% \mathrm{w} / \mathrm{w}$ of the original material. The yield of the low crystallinity cellulose (LCC-CC), obtained from $\alpha$-cellulose was $81.23 \% \mathrm{w} / \mathrm{w}$. Thus the yield of LCC-CC was $11.4 \% \mathrm{w} / \mathrm{w}$ of the starting material.

The results of the physicochemical properties investigated are shown in Table 1 . The results indicate a high level of purity of the cellulose materials. The organoleptic qualities of the ACCC and LCC-CC produced were good as the materials were odourless, tasteless, white and granular in texture. The values obtained for the total ash were very low. The total ash figure is of importance and indicates to some extent the amount of care taken in the preparation of the substance $^{18}$. The results were as specified in the British Pharmacopoeia 2004, except for the $\mathrm{pH}$ values of $\mathrm{AC}-\mathrm{CC}$ and $\mathrm{LCC}-\mathrm{CC}$ which were slightly above the official range of 5-7.5. This however, can be adjusted appropriately during the extraction processes by further washing and adding glacial acetic acid as buffer solution.

\section{Powder properties}

The powder properties of AC-CC and LCCCC are presented in Table 2 while the results of particle size analysis are shown in Fig 1 . The particle size is in the range of $70-1000 \mu \mathrm{m}$, and so the powders belong to the classification 'Conventional powder' ${ }^{\text {'19. }}$. About 46 and $70 \%$ of the particle population for AC-CC and LCC-CC, respectively, correspond to mean sieve aperture of $75 \mu \mathrm{m}$ (see Fig 1); and the calculated average particle diameters were 196.4 and $149.3 \mu \mathrm{m}$, respectively.

The true density of both cellulose materials were comparable (Table 2). Stamm ${ }^{20}$ had pointed out that a direct correlation exists between the degree of crystallinity of cellulose 
Table 1: $\quad$ Some physicochemical properties of AC-CC and LCC-CC

\begin{tabular}{ll}
\hline TESTS & AC-CC and LCC-CC \\
\hline Organoleptic & Odourless, white and tasteless \\
Identification & Turns violet-blue with iodinated $\mathrm{ZnCl}_{2}$ \\
Organic impurities & No red colour with acidified phloroglucinol \\
Starch and dextrins & No blue/reddish brown colour with iodine solution \\
pH & $8.4($ AC-CC) and 7.6 (LCC-CC) \\
Solubility (in ammoniacal solution of & Complete and no residue \\
copper tetrammine) & $<0.2 \%$ \\
Water -soluble substance & $2.4(0.14)$ (AC-CC) and 0.96 (0.08) (LCC-CC) \\
Total ash (\%) & \\
& Irregularly shaped fibrous particles which are mixture \\
Microscopy & of primary particles and spherical aggregates (AC- \\
& CC); more fibre-like in nature and largely primary \\
& particles (LCC-CC). \\
\hline Values are means and standard deviation in parenthesis; number of replicates, $\mathrm{N}=3$
\end{tabular}

and its true density when determined in a nonpolar liquid. Consequently, the comparable true density values of the cellulose powders are suggestive that they might have the same degree of crystallinity.

The bulkiness, (also known as specific bulk volume), defined as the reciprocal of bulk density, ${ }^{21}$ is lower for LCC-CC than for AC-CC (Table 2). This is due to higher proportion of small particle sizes in the powder population of LCC-CC. In powder material of different sizes, the smaller particles sift between the larger ones and tend to reduce the bulkiness ${ }^{21}$. Consequently, when packaging equal weights of these powders, a larger container would be required for $\mathrm{AC}-\mathrm{CC}$.

The loss on drying values for $\mathrm{AC}-\mathrm{CC}$ and LCC-CC were about 7.2 and $5.4 \%$, respectively. The LCC-CC value is within the official limit of 6 $\%$ stated in British Pharmacopoeia, 2004 ${ }^{13}$. Thus, LCC-CC would be most suitable, as diluent, in the formulation of hydrolysable drugs such as aspirin.

The flow properties of a powder are essential in determining its suitability as a direct compression excipient. The angle of repose, Hausner index and Carr's percent compressibility are considered as indirect measurements of powder flowability ${ }^{22}$. The angle of repose for AC-CC and LCC-CC were large (Table 2). Carter ${ }^{23}$, however observed that angle of repose between 35 and 45 is not in itself a sufficient criterion for predicting the flow properties of powders. Hausner index is indicative of interparticle friction while Carr's index shows the aptitude of a material to diminish in volume ${ }^{22}$. As the values of these indices increase, the flow of the powder decreases. In general however, Hausner ratio greater than 1.25, indicate poor flow; Carr's compressibility index below $16 \%$ indicate good flowability while values above $35 \%$ indicate cohesiveness $^{22}$. The flow indices showed that AC-CC and LCC-CC powders have poor flow. As a result, a glidant will be needed when these materials are to be used in solid dosage production processes.

Swelling which is generally accepted as an indication of tablet disintegration ability ${ }^{24}$ can be assessed by the determination of hydration capacity, swelling capacity and moisture sorption profile. The hydration capacity of ACCC (Table 2) indicates that it is capable of absorbing about four times its own weight of water and approximately twice more water than LCC-CC. The swelling capacities, which reflect the increase in volume of cellulose following water absorption, were 35.8 and $70.1 \%$ for 
Table 2: Powder properties of AC-CC and LCC-CC

\begin{tabular}{lll}
\hline Parameters & AC-CC & LCC-CC \\
\hline True density $(\mathrm{g} / \mathrm{ml})$ & $1.31(0.4)$ & $1.28(0.14)$ \\
Bulk density $(\mathrm{g} / \mathrm{ml})$ & $0.24(0.06)$ & $0.29(0.01)$ \\
Bulkiness $(\mathrm{ml} / \mathrm{g})$ & 4.17 & 3.45 \\
Tapped density $(\mathrm{g} / \mathrm{ml})$ & $0.34(0.08)$ & $0.41(0.01)$ \\
Porosity $(\%)$ & 81.7 & 77.3 \\
\hline
\end{tabular}

Flow properties:

(a) Angle of repose

(b) Hausner index

$39.4(0.89)$

$44.25(0.46)$

(c) Compressibility index (\%) 29.41

1.41

29.27

Hydration capacity

Swelling capacity (\%)

Average particle diameter $(\mu \mathrm{m})$

Loss on drying (\%)
$4.47(0.07)$

70.1 (3.57)

196.4

$7.2(0.26)$
$2.66(0.01)$

$35.76(0.03)$

149.3

$5.4(0.14)$

Values are means and standard deviations are in parenthesis; number of replicates, $\mathrm{N}=3$

LCC-CC and AC-CC, respectively, (Table 2). The higher hydration and swelling capacities observed for AC-CC compared to LCC-CC is due to the amorphous nature of $\alpha$-cellulose (AC$\mathrm{CC})$. The amorphous portion of cellulose material is known to be responsible for uptake of water and consequently swelling ${ }^{20}$. In addition, the low values for LCC-CC confirms that the phosphoric acid removed high proportions of the amorphous portion present in the a-cellulose (AC-CC) in the course of production of LCC-CC. Moreover, the results suggest that while both materials could function as disintegrants, AC-CC appears to a superior disintegrant.

The moisture sorption capacity is a measure of the moisture sensitivity of the material. The profile for AC-CC and LCC-CC (Fig. 2) are significantly different. It is higher for LCC-CC. This could have been due to higher proportion of small particles for LCC-CC resulting in greater total surface area. Furthermore, study of water sorption is of importance since it reflects the relative physical stability of tablets made from these materials when stored under humid conditions. In all, this property showed that the cellulose powders are sensitive to atmospheric moisture and should, therefore, be stored in an air-tight container.

\section{CONCLUSION}

The cellulose products, AC-CC and LCC-CC, obtained from corn cobs conformed to the official specifications in the British Pharmacopoeia (2004). The powder properties of these materials indicate that they could function as disintegrants and filler-diluents in pharmaceutical tableting.

\section{References}

1. Battiska AO. Microcrystalline Polymer Science, McGraw Hill, New York, 1975.

2. Von Engelbert Graf T. Cellulose, a valuable pharmaceutical aid and raw material. Dtsch. Apoth. Ztg. 1978; 118: 1625

3. Doelker E, Gurny R, Schurz J, Janosi A and Matin N. Degrees of crystallinity and polymerization of modified cellulose powders for direct tabletting. Powder Technol. 1987; 52: 207-213.

4. Landin $M$, Martinez-Pacheco R, Gomez-Amoza JL, Souto $C$, Concheiro $A$ and Rowe RC. Effect of country of origin on the properties of microcrystalline cellulose. Int. J. Pharm. 1993; 91: 123-131. 


\section{Ohwoavworhua et al}

5. Blaschek W. Cellulose, an interesting excipient for pharmaceutic use. Pharm. Unserer Zeit 1990; 19:73-81.

6. Voigt $R$ and Bornschein $M$. Lehrbuch der pharmazeutischen tecnologie. B. Auflage Verlagvolk und Gesunndgeit 1987; 155.

7. Greidinger DS, Bernnstein H and Epstein S. Degraded cellulose and its manufacture. US Patent 3397 198, 1968.

8. International Cellulose Company (Reno, Nevada, USA) Verfahren zum aurflosen von zellulose. Swiss Patent 79, 809, 1916.

9. Sachetto JP, St-Julian en G, Michel JP and Regnault A. Depolymerized cellulosic material with low crystallinity obtained from cellulosic fibers and process of its manufacture [acid hydrolysis with hydrochloric acid]. US Patent 4357 467, 1982.

10. Okhamafe AO and Azubuike CPC. Direct compression studies on low-cost cellulose derived from maize cob. J. Pharm. Sci. \& Pharm. Prac. 1994; 1: 26-29.

11. Audu-Peter JD, Ojile JE and Bhatia PG. Physicochemical and powder properties of alphaand microcrystalline- cellulose derived from maize cobs. J. Pharm. Biores. 2004; 1: 41-45.

12. Wei S, Kumar V, Banker GS. Phosphoric acid mediated decrystallization and depolymerization of cellulose. Preparation of low crystallinity cellulose- a new pharmaceutical excipient. Int. J. Pharm. 1996; 42: 175-181.

13. The British Pharmacopoeia, HMSO Press, London, 2004, Vol. 1.

14. Ansel CH, Popovich $\mathrm{GN}$ and Allen VL. Ansel's Pharmaceutical Dosage Forms and Drug Delivery Systems. Lippincott Williams and Wilkins, New York, 2005, pp 189.
15. Train D. Some aspects of the property of angle of repose of powders. J. Pharm. Pharmacol. 1958; 10: $127 T-134 T$.

16. Ohwoavworhua, FO, Ogah EO and Kunle OO. Preliminary investigation of physicochemical and functional properties of alpha cellulose obtained from waste paper - a potential pharmaceutical excipient. J. Raw Matr. Res. 2005; 2: 84-93.

17. Kornblum SS and Stoopak SB. A new tablet disintegrant agent: crosslinked polyvinylpyrollidone. J. Pharm. Sci. 1973; 62, 1: 43-49.

18. Evans WC. Trease and Evans' Pharmacognosy, ed 13, Bailliere Tindall, 1989, pp 339-377.

19. Barber TA. Pharmaceutical Particulate Matter. Analysis and Control. Interpharm Press, Buffalo Grove, IL. 1993, pp 266-349.

20. Stamm AF. Wood and Cellulose Science. The Ronald Press Company, New York. 1964, pp.132-165.

21. Martin A, Bustamante $P$ and Chun AHC. Physical Pharmacy, ed 4, Lippincott Williams and Wilkins, Baltimore, USA, 1993, pp 423-452.

22. Staniforth JN. Powder flow. In: Aulton ME (Ed). Pharmaceutics -The Science of Dosage form Design. Churchill Livingston, 1996, pp 600 -615.

23. Carter SJ (Ed). Tutorial Pharmacy, ed 6, Pitman Medical Publishing Co. Ltd., Tumbridge Well Kent England, 1972, pp 211-233.

24. Caramella C. Novel methods for disintegrant characterisation, part 1. Pharm. Technol. 1991; 3: 48-56. 